\title{
A REVIEW ON USAGE OF OPTIMIZATION METHODS IN GEOTHERMAL POWER GENERATION
}

\author{
Osman ÖZKARACA* \\ Department of Information Systems Engineering, Technology Faculty, Muğla Sıtkı Koçman University, Turkey, \\ osmanozkaraca@mu.edu.tr \\ (iD) https://orcid.org/0000-0002-0964-8757
}

Received: 26.12.2018, Accepted: 17.06.2018

*Corresponding author

Review Article

DOI: $10.22531 /$ muglajsci.437340

\begin{abstract}
In the study, a general assessment has been carried out on the optimization studies in geothermal power energy systems. In consideration of such assessments, an optimization guide has been proposed that can be helpful for researchers when used in optimization studies. This guide summarizes the processes in optimization process, points that needs to be paid attention in such processes, and some suggestions of example methods. Upon assessment of optimization studies on geothermal power systems, it is seen that meta-heuristic algorithms, which are high strategies for research of searching space especially through different methods, are highly successful. However, it has been concluded that studies have been carried out not on real-time optimization practices, but rather on the model in general.

Keywords: Optimization, geothermal, power generation, algorithms
\end{abstract}

\section{JEOTERMAL GÜÇ ÜRETIMINDE OPTIMIZASYON YÖNTEMLERİNIN KULLANIMINA İLISSKIN İNCELEME}

Öz

Gerçekleştirilen çalışmada jeotermal güç sistemlerinde gerçekleștirilen optimizasyon çalışmalarının genel bir değerlendirilmesi yapılmıştır. Bu değerlendirmeler ışığında optimizasyon çalışmalarında kullanılmak üzere araştırmacılara yardımcı olabilecek bir optimizasyon kılavuzu önerilmiştir. Bu kılavuz optimizasyon çalışmalarında hangi süreçlerin olacağını, buralarda nelere dikkat edilmesi gerektiğini ve örnek yöntemlerin neler olabileceğini okuyucuya özetlemektedir. Jeotermal sistemlerle ilgili optimizasyon çalışmaları değerlendirildiğinde özellikle farklı metotlarla arama uzayının araştırılması için yüksek bir strateji olan meta sezgisel algoritmaların oldukça başarılı olduğu görülmektedir. Bununla birlikte çalışmaların genel olarak model üzerinde gerçekleştiği, gerçek zamanlı optimizasyon uygulamalarının çok fazla olmadı̆̆ı sonucuna varılmıştır.

Anahtar Kelimeler: Optimizasyon, jeotermal, elektrik üretimi, algoritmalar

Cite

Özkaraca, 0., (2018). "A review on usage of optimization methods in geothermal power generation", Mugla Journal of Science and Technology, 4(1), 130-136.

\section{Introduction}

Geothermal energy is the thermal energy obtained from hot water, steam and dry steam as well as hot dry rocks formed by the heat accumulated within plutonic rocks being conveyed through fluids and stored in reservoirs. And the systems converting such thermal energy to electric energy are geothermal power plants. In fact, geothermal power plants are a type of thermal power plants. The difference is that the energy is obtained from underground heat, and not from coal. It is called clean energy as no $\mathrm{CO} 2$ or any other polluted wastes are released due to the output of the plant. In 2017, total geothermal heat capacity (sensible heat quantity) in Turkey has reached up to 15,500 MWt. By the end of 2017, 40 Geothermal Power Plants with 1,064 MW installed power correspond to approximately $1.2 \%$ of the total installed power in Turkey. Electricity generation from geothermal energy has been 5,970 GWh in 2017, and $2.02 \%$ of our electricity generation has been obtained from geothermal resources [1]. These data indicate that current resources of Turkey are not used very effectively and efficiently. Significantly high establishment and operation costs and difficulties in drilling studies due to geographical factors are some of the primary reasons behind it.

A geothermal power plant is designed according to the generation values of the resource, and operated based on the continuous electricity generation principle. Data obtained during the operation of the plant are recorded and assessed, and it is ensured that the plant operates in accordance with the performance determined with the design values. Geothermal power plant management 
consists of two main components. First one is conveying (generation and re-injection) the geothermal energy resource (reservoir), and the second one is converting the thermal energy to electric energy and supplying the generated electricity to the interconnected system. There are two basic strategical factors in operation of a geothermal power plant, which are; use of the geothermal resource in a sustainable way according to the operation capacity, and establishing the technical and administrative infrastructure for a secure and effective generation process. In this study, optimization studies performed for optimum operation of the geothermal power plant and ensure a sustainable capacity are assessed.

Lexical meaning of optimization can be defined as using the limited available resources in the most optimal way [2]. Within this respect, studies carried out to ensure best operation of geothermal power plants and sustain the available resources at the optimal level have been significantly increasing in recent years. Optimization is in fact a mathematical procedure and can be defined as maximizing or minimizing a function [2]. And optimization for geothermal plants is determining the mathematical model developed through using the most convenient parameters of points to be optimized and the values of variables in the criteria providing the best values in best objective criteria.

In this study, structure of a geothermal power plant has been addressed. And secondly, optimization methods and choice criteria have been addressed. Thirdly, optimization studies in the literature performed on such structures have been included in the study. Finally, assessments that may contribute to the studies in the literature and studies performed within this respect have been mentioned in the study.

\section{Geothermal Power Plants}

Geothermal system consists of three main factors: Heat source, reservoir and heat-conveying liquid. Geothermal energy is used in many areas from electricity generation to heating, and from chemical substance production to thermal tourism. Despite different classifications of different countries, geothermal power resources are divided into three groups, which are; low $\left(20-70{ }^{\circ} \mathrm{C}\right)$, medium (70-150 ${ }^{\circ} \mathrm{C}$ ) and high (higher than $\left.150{ }^{\circ} \mathrm{C}^{\prime}\right)$ enthalpy (temperature). Low and medium temperature fields, under today's technological and economic conditions, are used primarily in heating (greenhouse, building, agriculture), in industry (food drying, lumbering, paper and weaving industry, leather trade, cooling facilities) and in chemical substance production. However, based on the technologies developing day to day, electricity can also be generated from geothermal water with low tank temperature up to $150{ }^{\circ} \mathrm{C}$. Furthermore, studies have been continuing in order to utilize water at $60-90{ }^{\circ} \mathrm{C}$ in electricity generation using gases with low evaporation points (Freon, Isobutane, etc.) [3].

History of geothermal power plants dates back to 1990's. Although electricity generation was first carried out in the world in the Lardello field in Italy in 1904, it was only until 1950's that the interest towards electricity generation from geothermal energy aroused. First electricity generation from a vapor dominated field has been performed in Italy, and the first electricity generation from a water dominated field has been performed in New Zealand in 1950's [4].

A geothermal power plant contains a closed cycle, in which the geothermal fluid obtained from the geothermal energy generation well is processed, its thermal energy is taken, and it is re-injected to the reservoir through the injection well. Generally, a geothermal power plant can be examined in three main parts. First of these is geothermal energy generation. This is ensured through high-temperature heat sources reaching near the surface. Second one is generation and transfer of the electric energy. Electricity generation in a geothermal plant can vary depending on the characteristics of the source. There are dry steam plants, flash steam plants and binary cycle plants. These plant types can be seen in Figure 1 a-c.

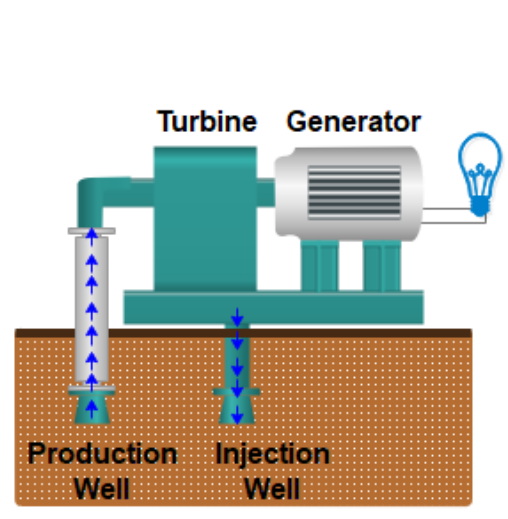

(a)

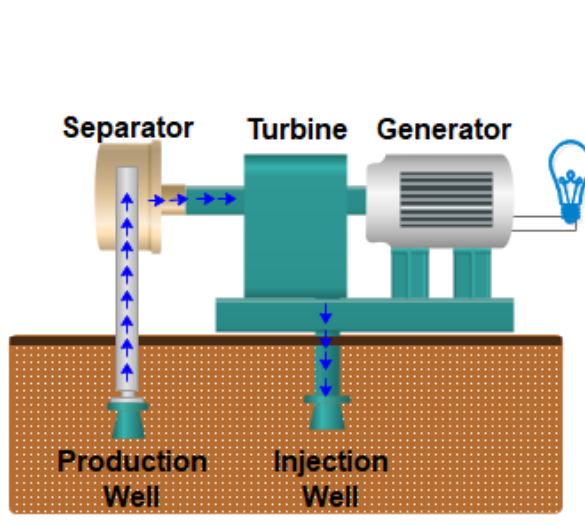

(b)

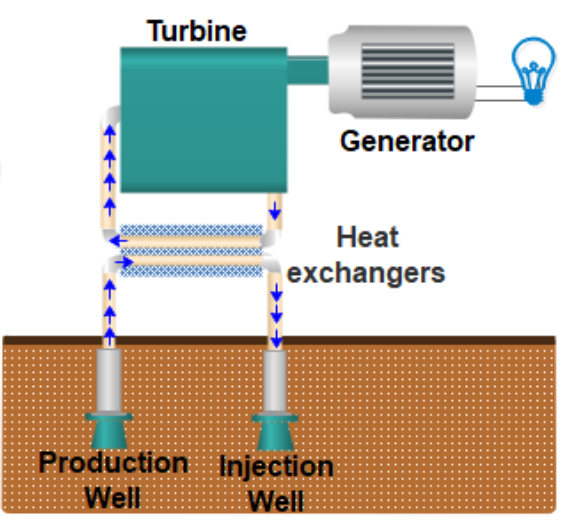

(c)

Figure 1. A) Dry steam plant b) Flash steam plant c) Binary cycle plant

In dry steam plants, dry steam generated from the well in order to turn the turbines is used directly. In flash steam plants, high-pressure fluid coming from the well is separated into water and steam in low-pressure 
separators, and the turbine is turned with the separated steam. And in binary cycle plants, heat of geothermal fluid is utilized, and the fluid, which evaporates at a lower temperature than water, is vaporized in the heatexchanger, and the turbine is turned with such vaporized fluid. And the last element of three main parts of a geothermal power plant is control and maintenance. These are the phases that optimization studies are carried out.

\section{Optimization}

Optimization has been defined differently by various disciplines. However, it can be defined in general as a technology ensuring that certain objectives are achieved by using the available resources in the system in the most efficient way. Optimization technology is utilized in effective, correct and real-time solutions of challenges faced in the real world through uses in speeding up the decision-making processes and increasing decision quality [5]. Most important developments in the optimization area were actualized by Newton and
Lagrange in the 18th century. Modeling and analysis are specified as two significant components in optimization. Modeling is mathematical expression of a problem faced in real life; and analysis includes achieving the best solution that provide such model [6]. In the development of optimization technology, researchers have primarily dealt with modeling. And today, studies on optimization are carried out through using different analysis methods and algorithms. Algorithms used in solving optimization problems can also be shortly referred to as optimization algorithms. Optimization algorithms are generally divided into two categories. These are deterministic algorithms and heuristic algorithms. Deterministic algorithms follow a precise sequence of actions. Thus, design variables and objective function can have the same values and repeat the same solution route. On the other hand, heuristic algorithms always involves a randomness. Furthermore, different methods are developed through hybrid use of deterministic and heuristic methods. A classification of the optimization algorithm is demonstrated in Figure 2 [7].

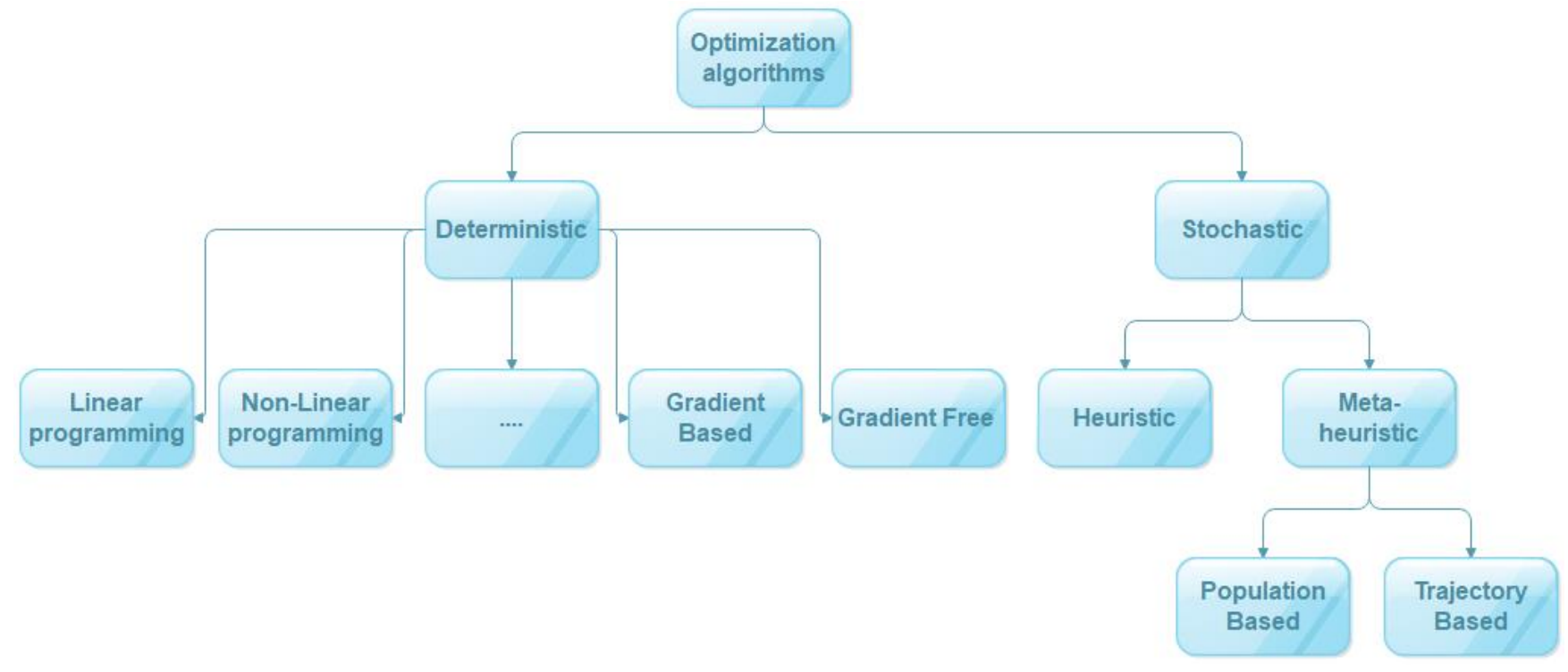

Figure 2. Classification of optimization algorithms [7]

\section{Literature Review}

With the increase of demand in sustainable energy, which is an inexpensive, clean energy, interest in geothermal technologies has been increasing in recent years. Becoming more efficient especially with energy conversion technologies, geothermal systems has started to be used outside the conventional systems. And one of the most important steps to this has been taken with the integration of optimization processes into geothermal systems. Increasing scientific studies in recent years is the most significant proof within this respect. In conclusion of the scan result of "optimization" and "geothermal plant" words through Web of Science, it can be seen in Figure 3 that studies has been increasing each year since 1994. The fact that 64 studies has been performed in first six months of 2018, as it is seen in the diagram, demonstrates that this year will exceed the previous year's towards the end of the year.

Knowing and understanding the studies of previous years in the literature will shed light on future studies. At this point, summarizing the methods used for optimization, the parameters examined, and the functions preferred for the objective function will help researchers in their future studies. 


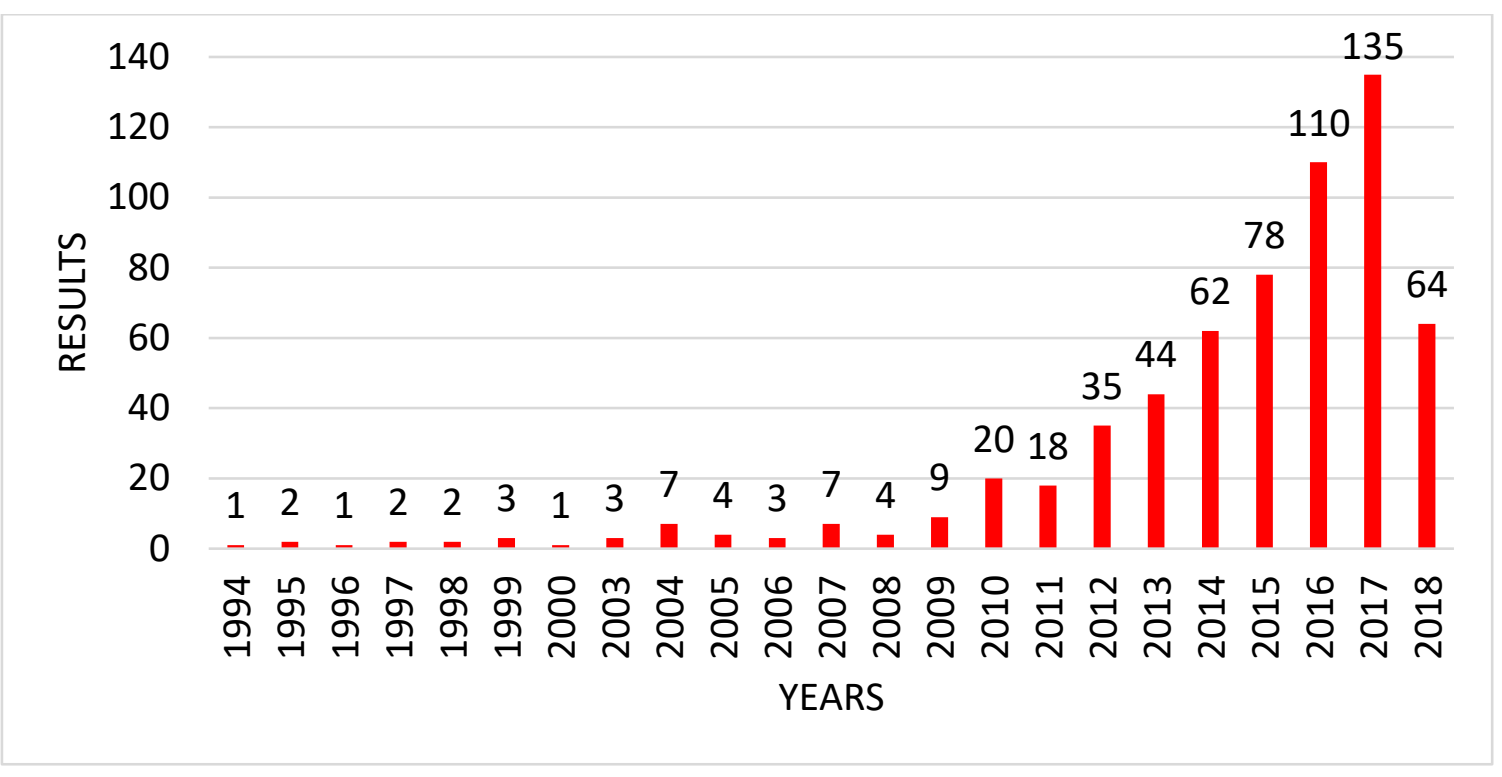

Figure 3. Distribution of studies performed according to years

In this study, optimization studies in the literature have been assessed in various ways. For example, mathematical optimization, parametric optimization [8], exergoeconomic optimization, thermodynamic optimization are some of these groups. Upon examination of the methods in this classification, especially with respect to studies in recent years, it is seen that heuristic studies are widely preferred for optimization of geothermal systems. For example, Hamid Saffari et al. have conducted a study using the Artificial Bee Colony $(\mathrm{ABC})$ algorithm in order that the Kalina cycle in the geothermal power plant reaches the optimal thermal and exergy efficiency. It has been reported that the mechanism of this new, powerful, multipurpose and multi-mode $A B C$ optimization algorithm remarkably increase convergence rate and accuracy of solutions compared to GA, PSO and DE algorithms [9].

Joshua Clarke and James T. McLeskey developed a particle swarm optimization-based method in their study in order to determine the optimal use of a superheater and/or recuperator in a binary geothermal power plant [10].

In the study, especially smart system applications have been frequently used in the optimization of geothermal systems. Genetic Algorithm and Artificial Neural Networks are the primary smart system applications. For example, Oğuz Arslan researched the use of Kalina cycle system-34 (KCS-34) in the electricity generation procured from Simav geothermal field. In the study, Artificial Neural Network (ANN) has been used to determine optimal operating conditions of processes requiring expertise. In this study, a back-propagation learning algorithm has been used in the network with three different formats, namely the LevenbergMarguardt (LM), Pola-Ribiere Conjugate Gradient (CGP) and Scaled Conjugate Gradient (SCG). The aim has been to find the best approach. It has been reported that the most convenient algorithm is LM at a single hidden layer with 7 neurons. It has been ensured that the attained weights are used in the optimization process, combining the concepts of life cycle and cost [11].

In another study conducted by Halit Arat and Oğuz Arslan, the purpose has been to attain an optimal design of the geothermal heat pump supported district heating system (GHPDHS) using a new, multistage ANN model. The proposed ANN model basically consists of two stages. While the first stage has a single level, the second one consists of three levels. In conclusion, it has been demonstrated in this study that the multistage study with a multilevel ANN model provided more time and convenience, and that it can be easily applied to geothermal power plants [12].

In the study by Hadi Ghaebi et al., a single and multipurpose optimization has been carried out in consideration of the thermal efficiency, exergy efficiency and total unit cost of the system using the Genetic algorithm. In the study, a convenient combination of the Kalina cycle (KC) and ejector refrigerating cycle (ERC) as well as a new combined power and ejector refrigerating cycle has been proposed in order to generate a power output and a cooling output simultaneously. Furthermore, it ensures that optimal design variables, including GA steam generator pressure, evaporator temperature, condenser pinch point temperature, heat source temperature, ammonia concentration and the expander rate, are determined [13].

In the study by Muhammad Imran et al., using the Nondominated Sorting Genetic Algorithm-II (NSGA-II), hydraulic and thermal design model of the chevron type plated evaporator has been developed and ensured optimization of geometric parameters for a lowtemperature geothermal ORC system. Multi objective function has been used in the study. As objective functions are contradicting, a single value of decision variables cannot predict all objective functions at the same time. Therefore, optimization results in the study, closing the gap between the costs of pressure reducer 
and the evaporator, are provided as the Pareto Front solution [14].

Another commonly used smart method is fuzzy logic. For example, Masoud Heydari Aghagol et al. have conducted a Fuzzy Logic-based study in order to determine potential geothermal areas. In this study, 5 potential factors effective in geothermal, namely the land surface temperature (LST), Lithology, Superficial evidence, Geomagnetic and Fault, have been used [15]

Upon assessment of such studies, it is seen that metaheuristic algorithms developed inspired especially by natural processes are more successful [16]. For instance, in a study by Joshua Clarke et al., the particle swarm optimization and performance of the genetic algorithm have been compared with the purpose of achieving a limited, nonlinear, simulation-based optimization of a double flash geothermal power plant. In the study, particle swarm optimization reached better (higher) objective function values. It has been seen that genetic algorithm reached faster and closer values while causing the loss of solution diversity [17].

In review of studies in the literature, such studies can also be fictitiously classified based on objective functions. These are single objective function [18] and multi objective function [19], [14] studies. In single objective function studies, mathematical functions such as the total quantity of energy generated throughout the life of the system [20] or rate of the heat exchanger to the total surface area output power [18] are used. These formulations are created and developed based on the laws of thermodynamics, and optimization results are assessed with regards to costs. For example, in the study conducted by Jozsef Hecht-Méndez et al., the objective function has been formulated for minimizing the thermal effect on the surface, and as a result, improving the heat pump performance in order to avoid over-temperature abnormalities [21]. And in the study carried out by researchers Min-Hsiung Yang and Rong-Hua Yeh, economic optimization of a transcritical Rankine cycle system in a geothermal power plant has been researched. In the study, an economic parameter of net power output index, which is the ratio of net power output to the cost, has been applied in order to optimize the system. As a result, it has been found out that geothermal temperatures are effective on thermodynamic and economic optimizations [21].

Studies developed in recent years, adopting multiple objective functions, allow for system analyses from different perspectives [22]. For example, Hadi Ghaebi et al. carried out a multi objective optimization in their study. Fist objective function is maximizing thermal and exergy efficiency, and the other one is minimizing the total product cost [23].

Yajing Zhao et al. have carried out two multi objective optimization in order to achieve the maximum exergy efficiency for the total system and minimum mean cost per unit for exergy products in each unit [24].
Upon review of studies in the literature, it is observed that the existing power plants are assessed systematically or through their components. In addition to these studies, strategical studies stand out. Fox example, Saeid Jalilinasrabady et al. have developed mathematical models for energy and exergy flows of the Sabalan geothermal field in Iran, and proposed a double flash cycle system for Sabalan plant according to the results [25]. Similarly, Oğuzhan Arslan and Ramazan Köse proposed many complex structures in their study for achieving a more efficient use of energy of the geothermal fluid. In the study, electricity generation possibility with binary cycle has been researched, and suggestions have been made for the waste geothermal fluid. Within this context, twenty one different models have been created and analyzed using the exergy and LCC (life cycle cost) methods [26].

In the study conducted by Ahmet Coşkun et al., it has been aimed to make a rational thermodynamic and economic comparison of various cycles for a certain resource through researching the most efficient utilization method of a geothermal resource. Double flash, binary, combined flash/binary and Kalina cycle are included in the considered cycles. Maximum power output and cycles selected for generating energy and exergy efficiency have been optimized for turbine input pressure [27].

In the study conducted by İsmail Yabanova and Ali Keçebaş, a new and optimal control strategy has been developed for developing the ANN modeling for geothermal area heating systems and maximizing the exergy efficiency using such systems. With the proposed control strategy, energy efficiency and cost saving of the system has been increased by $13 \%$ [28]. In a study conducted by researchers Amin Mohammadi and Mehdi Mehrpooya, a modified Kalina cycle is connected to a reverse osmosis system in order to provide heating, refrigeration, power and drinking water. Thus, energy and exergy analyses as well as performance of the system have been assessed. In the study, the effect of thermodynamic parameters on the system performance has been examined through adopting the sensitivity analysis [29].

When the studies are reviewed, it is seen that especially exergy analyses along with optimization are carried out. Exergy is defined as the maximum available theoretical work in a state that the system interacts solely with its environment and establishes a full thermodynamic balance with its environment [30]. Exergy analyses in some way assess the success of the optimization. For example, Nugroho Agung Pambudi et al. have carried out exergy analysis and optimization of a single flash geothermal plant. In the study, exergy flow and efficiency for the turbine, condenser and the whole plant have also been calculated [31].

And in some studies, success of the optimization has been assessed based on the generated energy quantity. Researchers Neda Kazemi and Fereshteh Samadi have proposed a new, organic Rankine cycle using the basic 
organic Rankine cycle, regenerative organic Rankine cycle and two-stage evaporator organic Rankine cycle in order to increase the energy generation from geothermal resources. Optimization results of the study indicate that in the newly proposed organic Rankine cycle, compared to the basic organic Rankine cycle, thermal and exergy efficiencies in work flows have increased, and energy damage decreased especially in evaporators [32]. In the study conducted by A. Aali et al., a new flash-binary cycle has been proposed for electricity generation through using the real values and characteristics of the Iran Sabalan geothermal field, taking into consideration the temperature as well as pressure differences of current wells [22].

\section{Conclusion and Recommendations}

In this study, many studies on geothermal systems have been assessed from different perspectives. In consideration of such assessments, a flow diagram has been prepared, as seen in Figure 4, in order to shed light on future studies of researchers.

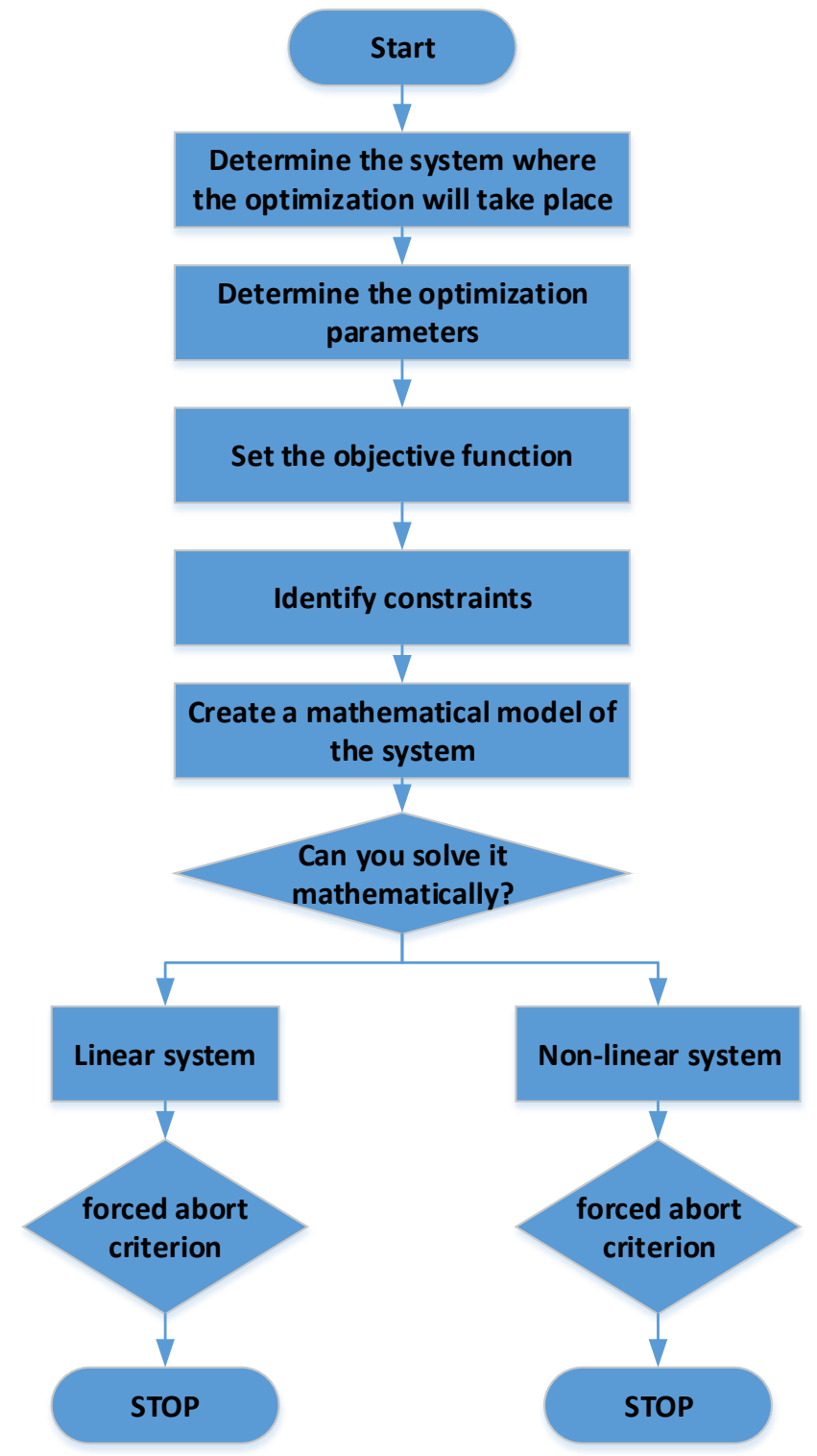

Figure 4. Steps of optimization process
According to this diagram, steps followed during optimization studies in geothermal systems have been explicitly indicated. It has been observed, with a general assessment of optimization studies in the literature that meta-heuristic algorithms, which have recently allowed for combining the developing heuristic methods, are much better than the conventional techniques due to the fact that they approach the global speed fast and ensure a high success rate. It has been seen that meta-heuristic algorithms are highly successful at dealing with optimization problems thanks to their highly complex, nonlinear and multidimensional processing capabilities. The reason behind it is that a meta-heuristic algorithm aims to attain the best result in the searching space through using the lowest heuristic as well in order to produce high-quality solutions effectively.

According to the results attained in the conducted studies, using high-tech for energy generation from available geothermal heat sources is an effective strategy for the development of sustainable energy; however, integration of advanced optimization methods with these technologies will extend such sustainability in geothermal systems.

Furthermore, upon reviewing the literature, it is seen that there is not an available real-time hybrid operation created through integration with the optimization of an expert system. For example, a smart control study, which calculates the optimization parameters in geothermal systems according to the varying instant conditions and apply such parameters to the system, has not been found. The reason behind it could be the fact that such facilities do not disrupt their ongoing operation for academical or R\&D activities. As 1-hour interruption of this type of facilities will mean a significant financial loss for the business owner.

\section{Acknowledgment}

This paper has been granted by the Muğla Sıtkı Koçman University Research Projects Coordination Office through Project Grant Number: 18/061

\section{References}

[1] Enerji ve Tabi kaynaklar Bakanlığı, Available: http://www.enerji.gov.tr/tr-TR/Sayfalar/Jeotermal. [Accessed: 1204 2018].

[2] B. Bunday, Basic Optimisation Methods, London: Edward Arnold Ltd, 1984.

[3] F. Gümüş, "Edremit Körfezi Enerji Potansiyeli ve Enerji Kaynakları ve Geleceğin Teknolojisi", 2015. Available: https://www.muhendisbeyinler.net/forum/dosyalar/en erji-kaynaklari-mb-yayinlari-mak-muh-furkan-gumuspdf.114/. [Accessed: 1301 2018].

[4] A. Özdemir, "Jeotermal enerji ve elektrik üretimi", Available:

http://www.jeotermal.com/dokumanlar/dosyalar/3792 175-60.pdf. [Accessed: 133 2018].

[5] W. Winston, Operations Research: Applicatios and Algorithms, Belmont, CA.: International Thomson Publishing, 2003.

[6] M. Türkay, "Optimizasyon modelleri ve çözüm metodları", Available: 
http://home.ku.edu.tr/ mturkay/indr501/Optimizasyo n.pdf.

[7] X. Yang, Engineering Optimization, Hoboken, NJ, USA: John Wiley \& Sons, Inc., 2010.

[8] Q. Liu, A. Shen and Y. Duan, "Parametric optimization and performance analyses of geothermal organic Rankine cycles using R600a/R601a mixtures as working fluids", Applied Energy, vol. 148, pp. 410-420, 2015.

[9] H. Saffari, S. Sadeghi, M. Khoshzat and P. Mehregan, "Thermodynamic analysis and optimization of a geothermal Kalina cycle system using Artificial Bee Colony algorithm", Renewable Energy, 89, pp. 154-167, 2016.

[10] J. Clarke and J. T. McLeskey, "Multi-objective particle swarm optimization of binary geothermal power plants", Applied Energy, vol 138, pp. 302-314, 2015.

[11] O. Arslan, "Power generation from medium temperature geothermal resources: ANN-based optimization of Kalina cycle system-34”, Energy, vol 36, pp. 2528-2534, 2011.

[12] H. Arat and O. Arslan, "Optimization of district heating system aided by geothermal heat pump: A novel multistage with multilevel ANN modelling", Applied Thermal Engineering, vol 111, pp. 608-623, 2017.

[13] H. Ghaebi, T. Parikhani, H. Rostamzadeh and B. Farhang, "Thermodynamic and thermoeconomic analysis and optimization of a novel combined cooling and power (CCP) cycle by integrating of ejector refrigeration and Kalina cycles", Energy, vol 139, pp. 262-276, 2017.

[14] M. Imran, M. Usman, B.-S. Park and H.-J. Kim, "Multiobjective optimization of evaporator of organic Rankine cycle (ORC) for low temperature geothermal heat source", Applied Thermal Engineering, vol 80, pp. 1-9, 2015.

[15] M. H. Aghagol, R. Hamidi and M. R. Heyhat, "Assess the potential of geothermal resources using fuzzy logic and binary index overlay (Case Study: South Khorasan province, eastern Iran)", Journal of Tethys, vol 4, no. 3, pp. 221-241, 2016.

[16] M. Madić, D. Marković and M. Radovanović, "Comparison of meta-heuristic algorithms for solving machining optimization problems", Facta Universitatis, Series: Mechanical Engineering, vol 11, no. 1, pp. 29-44, 2013.

[17] J. Clarke, L. McLay and J. T. McLeskey, "Comparison of genetic algorithm to particle swarm for constrained simulation-based optimization of a geothermal power plant", Advanced Engineering Informatics, vol 28, pp. 8190, 2014

[18] R. S. El-Emam and I. Dincer, "Exergy and exergoeconomic analyses and optimization of geothermal organic Rankine cycle", Applied Thermal Engineering, vol 59, pp. 435-444, 2013.

[19] M.H. Ahmadi; M. Mehrpooya; F. Pourfayaz "Thermodynamic and exergy analysis and optimization of a transcritical $\mathrm{CO} 2$ power cycle driven by geothermal energy with liquefied natural gas as its heat sink", vol 109, pp. 640-652, 2016.

[20] M. Pollet, L. Gosselin, J. Dallaire and F. Mathieu-Potvin, "Optimization of geothermal power plant design for evolving operating", Applied Thermal Engineering, vol 134, pp. 118-129, 2018.

[21] J. Hecht-Méndez, M. D. Paly, M. Beck and P. Bayer, "Optimization of energy extraction for vertical closedloop geothermal systems considering groundwater flow", Energy Conversion and Management, vol 66, pp. 1-10, 2013.

[22] A. Aali, N. Pourmahmoud and V. Zare, "Exergoeconomic analysis and multi-objective optimization of a novel combined flash-binary cycle for Sabalan geothermal power plant in Iran", Energy Conversion and Management, vol 143, p. 377-390, 2017.

[23] H. Ghaebi, A. S. Namin and H. Rostamzadeh, "Performance assessment and optimization of a novel multi-generation system from thermodynamic and thermoeconomic viewpoints", Energy Conversion and Management, vol 165, pp. 419-439, 2018.

[24] Y. Zhao, J. Wang, L. Cao and Y. Wang, "Comprehensive analysis and parametric optimization of a CCP (combined cooling and power) system driven by geothermal source", Energy, vol 97, pp. 470-487, 2016.

[25] S. Jalilinasrabady, R. Itoi, P. Valdimarsson, G. Saevarsdottir and H. Fujii, "Flash cycle optimization of Sabalan geothermal power plant employing exergy concept", Geothermics, vol 43, pp. 75-82, 2012.

[26] O. Arslan and R. Köse, "Exergoeconomic optimization of integrated geothermal system in Simav, Kutahya", Energy Conversion and Management, vol 51, p. 663-676, 2010.

[27] A. Coskun, A. Bolatturk and M. Kanoglu, "Thermodynamic and economic analysis and optimization of power cycles for a medium temperature geothermal resource", Energy Conversion and Management, vol 78, pp. 39-49, 2014.

[28] İ. Yabanova and A. Keçebaş, "Development of ANN model for geothermal district heating system and a novel PIDbased control strategy", Applied Thermal Engineering, vol 51, pp. 908-916, 2013.

[29] A. Mohammadi and M. Mehrpooya, "Energy and exergy analyses of a combined desalination and CCHP system driven by geothermal energy", Applied Thermal Engineering, vol 116, p. 685-694, 2017.

[30] G. Tsatsaronis, "Recent developments in exergy analysis and exergoeconomics", International Journal of Exergy, Inderscience Enterprises Ltd, 2008, pp. 489-499.

[31] N. A. Pambudi, R. Itoi, S. Jalilinasrabady and K. Jaelani, "Exergy analysis and optimization of Dieng single-flash geothermal power plant", Energy Conversion and Management, vol 78, pp. 405-411, 2014.

[32] N. Kazemi and F. Samadi, "Thermodynamic, economic and thermo-economic optimization of a new proposed organic Rankine cycle for energy production from geothermal resources", Energy Conversion and Management, vol 121, p. 391-401, 2016.

[33] M.-H. Yang and R.-H. Yeh, "Economic performances optimization of the transcritical Rankine cycle systems in geothermal application", Energy Conversion and Management, vol 95, pp. 20-31, 2015. 